\title{
Participacion de la familia en la ejecución del Programa Educativo Individual (PEI) en la escuela de lenguaje
}

\author{
Luis Enrique Pincheira Muñoz*
}

\begin{abstract}
Resumen
Estas reflexiones pretenden destacar que la participación de la familia es de vital importancia, por lo tanto, la escuela debe realizar esfuerzos significativos para involucrarla más allá de las tradicionales tareas que comparten en el proceso educativo. Para desarrollar un trabajo colaborativo es primordial que la escuela y familia trabajen en conjunto, la escuela es la encargada de abrir la puerta a la participación y compromiso de la familia en educación. El Profesor de Educación Diferencial debe involucrar a su familia para lograr la participación y colaboración para centrar esfuerzos en la implementación del Programa de Educativo Individual (PEI) conforme a lo establecido en el decreto 1300/02 que rige la Escuela Especial de Lenguaje, a través de actividades plasmadas en un cuaderno o carpeta específica.
\end{abstract}

Palabras clave: Escuela Especial de Lenguaje, Programa Educativo Individual (PEI) Familia, Educador Diferencial.

\section{Family involvement in the implementation of the Individual Education Programme (IEP) at a language school}

\begin{abstract}
The following reflections attempt to highlight the importance of family involvement and the need for schools to significantly include family members into the educational process of their children. Schools and families should work in collaboration and it is the school which must open spaces for family collaboration and commitment. The Professor of Special Needs Education must get family members involved in order to achieve participation and collaboration. This allows concentrating efforts on the implementation of the Individual Education Programme (IEP) as established by decree I300/02 currently ruling special language schools through activities expressed in a specific notebook or folder.
\end{abstract}

Keywords: Special Language Schools; Individual Education Programme (IEP); Family; Special Needs Educator.

* Profesor de Educación Diferencial mención Audición y Lenguaje. Magíster en Educación mención Escuela y Comunidad. UMCE Dpto. Educación Continua. lpincheira46@hotmail.com 


\section{Introducción}

La familia es el primer contexto social del niño/a, donde aprende sus primeros comportamientos interpersonales. Padres, hermanos y otros adultos cumplen el rol de primeros modelos en la formación socioafectiva, en relación a comportamiento, vinculación emocional, sistemas de creencias y valores por medio de sus prácticas y discursos (Arón y Milicic, 1999).

Hoy las orientaciones educativas en Educación Especial, señala a la familia como un agente determinante en el acompañamiento del proceso escolar de su hijo/a con Necesidades Educativas Especiales. Por tal motivo surge el desafío del Profesor/a de Educación Diferencial de involucrar la participación de la familia en la ejecución y reforzamiento diario de las actividades del Programa Educativo Individual (PEI).

Es por esto que la participación de la familia en el proceso educativo del niño, tiene un efecto significativo ya que en el hogar se entrega valores, principios y conocimientos básicos que son sustento fundamental del aprendizaje, para alcanzar las exigencias académicas que imperan hoy.

El Programa Educativo Individual (PEI) permite dar respuesta a necesidades educativas particulares de cada alumno/a matriculado en una Escuela de Lenguaje; dicho programa se desarrolla en un período de la jornada educativa con un tiempo limitado, el cual no es suficiente para su potenciación; debe ser continuo y permanente de modo que produzca logros y avances, para lo cual se hace crucial el refuerzo de las actividades propuestas en el hogar.

\section{Documentación y revisión teórica que avalan la propuesta}

La colaboración de la familia en la aplicación del Programa Educativo Individual (PEI) es de vital importancia como lo señala el decreto I300/2002; dicha participación es importante, porque la familia como actor interesado, interactúa en forma diaria con el hijo/a, y de esta forma potencia las actividades propuestas en el cuaderno enviado por el Educador/a Diferencial. 
Por consiguiente, se hace necesario que entre el/la Educador/a Diferencial y su familia exista un diálogo permanente en relación a mantener claridad en realizar las actividades o ejercicios específicos en el hogar; como se plantea en la Política Educativa de Educación Especial, uno de los desafíos es informar y orientar a la familia para que ésta colabore en el proceso educativo.

La participación de la familia es un pilar fundamental en la educación del hijo/a, como lo señala De Bruin y Krol (2003): "Toda escuela que pretenda aportar significativamente en la vida y formación de su niño/a deberá encontrar maneras de ofrecer accesos y soporte a los padres, y lograr una alianza con ellos", es por esto que el trabajo colaborativo que se da entre el Educador/a Especialista y la familia, permite que ésta sea partícipe de la enseñanza que se pretende impartir favoreciendo en el hogar la ejecución de las actividades del Programa Educativo Individual, potenciando el trabajo realizado en aula con el fin de superar las necesidades Educativas Especiales.

Es importante destacar que la familia tiene un compromiso importante con su hijo/a. Como lo señala el decreto I300/02, dicha participación es responsabilidad de la Escuela Especial de Lenguaje de lograr involucrar activamente a la familia en entrevistas, reuniones y programación de visitas (hogar o establecimiento educacional), aplicación de anamnesis, orientación en las actividades de apoyo a realizar en el hogar, realización de talleres de habilidades sociales y comunicación, escuelas para padres, participación en reuniones técnicas de profesores y/o en actividades del Gabinete Técnico.

La Política de Educación Especial (2005) constituye una nueva etapa en la Reforma Educacional, donde señala que niños, jóvenes y adultos que presentan Necesidades Educativas Especiales hagan realidad el derecho a la educación.

La Educación Especial debe asegurar la igualdad de oportunidades en un continuo esfuerzo para dar respuesta y alcanzar los fines propuestos. Esta política reconoce el derecho de la familia a elegir la opción educativa que considere más adecuada para su hijo/a. Para ejercer este derecho, la familia debe estar informada de las distintas opciones educativas que existen en el sistema escolar. Motivo por 
el cual se hace importante el apoyo a la familia para que ésta ejerza su derecho en plenitud.

Otro desafío es informar y orientar a la familia para que ésta colabore en el proceso educativo de su hijo/a y sea un recurso permanente en la definición, gestión y apoyo para el control y fiscalización social del proceso y proyecto educativo del establecimiento.

Actuales principios de la Política de Educación Especial:

- La educación es un derecho para todos.

- La diversidad es una fuente de riqueza para el desarrollo y aprendizaje de las comunidades educativas.

- Construcción de una sociedad más justa, democrática y solidaria.

- El Mejoramiento de la calidad, equidad y pertinencia de la oferta educativa exige atender a las personas que presentan necesidades educativas especiales.

- La participación activa e informada de la familia, los docentes, los alumnos y la comunidad en las distintas instancias del proceso educativo.

En nuestro país la Escuela de Lenguaje se rige por el decreto de Ley $\mathrm{N}^{\circ} 1300 / 2002$, que aprueba planes y programas de estudio para alumnos/as con Trastornos Específicos del Lenguaje (TEL). Su principal objetivo es brindar una atención especializada cuyo diagnóstico lo realiza un profesional fonoaudiólogo o derivado desde algún centro de atención en salud.

El Decreto 170/2010 señala como objetivo clarificar y reiterar algunos aspectos de la normativa de modo de garantizar una adecuada aplicación de los planes y programas de estudio establecidos en el decreto 1300/2000, y de resguardar el correcto ingreso de los alumnos a estas escuelas.

El diagnóstico del profesional fonoaudiólogo debe ser complementado con una evaluación del profesional especialista a cargo del curso/ nivel, quien determinará las necesidades Educativas Especiales que se derivan del Trastorno Específico de Lenguaje (TEL). 
El decreto cuenta con dos planes de estudio, el primero de carácter general y el segundo más específico; en relación al plan general, está centrado en las matrices curriculares de los decretos supremos de Educación $\mathrm{N}^{\circ}$ s 289 de 2001 y 40 de 1996, modificado por el $N^{\circ} 240$ de 1999, con adecuaciones curriculares pertinentes a las Necesidades Educativas Especiales que presenta cada alumno, y un plan específico que resuelva sus necesidades de aprendizaje derivadas del Trastorno Específico de Lenguaje (TEL).

El plan específico contempla la atención de la Fonoaudióloga en sesiones de 30 minutos de forma individual o colectiva hasta 3 niños como máximo, además dicho plan específico contempla el Programa Educativo Individual (PEI) que lo ejecuta el Educador/a Diferencial como instrumento curricular que permite organizar actividades de enseñanza-aprendizaje en relación a las dificultades específicas de Lenguaje de cada alumno/a, orienta su práctica pedagógica con respecto a sus objetivos planteados, a través de una serie de actividades a desarrollar, como estrategias y recursos a emplear con el fin de potenciar y desarrollar los aspectos deficitarios del Lenguaje en cada alumno/a.

\section{Reflexiones finales}

La relación familia y escuela conlleva a múltiples beneficios que permite al alumno/a con Trastorno Específico del Lenguaje (TEL) alcanzar diversos beneficios que se reflejan en una mejora de su dificultad, que genera una actitud positiva hacia el aprendizaje. Es crucial que el/la Educador/a Diferencial pueda tomar iniciativas más allá de lo cotidiano para desarrollar el Programa Educativo Individual para ser ejecutado.

La Escuela de Lenguaje, que logra motivar a la familia como otro agente colaborador, denota un sentimiento de pertenencia, sintiéndose participe activo en la educación, lo que trae consigo una mejor relación con el profesor(a) en relación a la comprensión del trabajo que se realiza.

El/la Educador/a Diferencial, al crear una alianza con la familia, le permite un mayor conocimiento del contexto sociocultural y 
relacionar el progreso y avances de las dificultades de Lenguaje que presenta cada alumno/a.

El trabajo colaborativo entre familia y Educador Diferencial permite desarrollar acciones inclusivas que conllevan un mayor compromiso en enriquecer las experiencias de lenguaje y habilidades de comunicación del alumno/a.

Es importante señalar que las habilidades lingüísticas que adquiere el alumno/a en el aula, deben ser continuamente reforzadas en el hogar. Puesto que la cantidad y calidad de las interacciones lingüísticas que se producen en el entorno familiar tienen un efecto significativo de superar sus dificultades del lenguaje.

El educador Diferencial enfrenta un desafío más allá de la clásica reunión de apoderados, de buscar otras alternativas de contacto, para involucrar de manera eficaz a la familia en la aplicación práctica del Programa Educativo Individual (PEI).

Es crucial desarrollar un trabajo colaborativo, puesto que el Programa de Enseñanza Personalizada (PEI) debe ser ejecutado en forma eficiente y eficaz para dar cumplimiento a los objetivos propuestos y recibir una instrucción adecuada los progenitores.

\section{Referencias bibliográficas}

Arón y Milicic (1999). Clima social escolar y desarrollo personal. Un programa de mejoramiento. Santiago: Editorial Andrés Bello.

De Bruin, A. \& Krol, B. (Ed.). (2003). Family literacy. From theory to practice. Newark, Delawere: International Reading Association.

Ministerio de Educación (200I). Bases Curriculares de la Educación Parvularia.

Ministerio de Educación (2002). Política de Participación de Padres, Madres y Apoderados en el Sistema Educativo. Chile.

Mineduc (2005). Política de Educación Especial Nuestro Compromiso con la Diversidad. Gobierno de Chile.

Mineduc (2009). Decreto I70/2010. Normas para determinar alumno/a con NEE beneficiarios de Subvención para Educación Especial.

Mineduc (2002). Decreto I300/2002. Aprueba Planes y Programa de estudio para alumnos con Trastornos Específicos del Lenguaje. 